\title{
Morphologic Pattern of Diseases in Gastric Biopsies and Role of Helicobacter Pylori in Chronic Gastritis at a Nigerian Teaching Hospital
}

\author{
Usman Bello $^{1^{*}}$ and Abubakar S Maiyaki ${ }^{2}$ \\ ${ }^{1}$ Department of Morbid Anatomy and Forensic Medicine, College of Health Sciences, Usmanu Danfodio University, Sokoto, Nigeria \\ ${ }^{2}$ Department of Medicine, Gastroenterology Unit, College of Health Sciences, Usmanu Danfodio University, Sokoto Nigeria
}

DOI: $10.36348 /$ sjpm.2021.v06i02.005 $\quad$ | Received: 14.01.2021 | Accepted: 25.01.2021 | Published: 13.02 .2021

*Corresponding author: Dr. Usman Bello (MBBS, FMC Path)

\section{Abstract}

Background: Helicobacter pylori infection of the gastric mucosa is the most important aetiologic agent identified to cause chronic gastritis with consequences ranging from acute ulceration to the development of debilitating gastric cancer. Histopathologic characterisation of the disease progression from gastric biopsies is frequently required. Objectives: To determine the histopathologic pattern of gastric biopsies categorised chronic gastritis using updated Sydney classification and determined the role of Helicobacter pylori in chronic gastritis in our centre. Methodology: A retrospective study of all the gastric biopsies received in the department of Histopathology, Usmanu Danfodio University Teaching Hospital, and Sokoto between the years 2011-2020. Formalin fixed, paraffin embedded tissue blocks and slides stained with routine, special and immunohistochemical stains were used. Microscopic features detailing different pathologies were analysed and chronic gastritis were classified based on updated Sydney classification. Information on age, sex and duration of disease was retrieved from request cards and case folders. Collected data analyzed using SPSS version 20. Results: There were 252 gastric biopsies received, 137 male and 115 female patients and a ratio of 1.2:1. Their ages ranged from 16 to 82 years and peak in the $6^{\text {th }}$ decade of life with a mean age of 46.5 years. The most common diagnosis was chronic gastritis and constitutes $85.5 \%$ (215 cases), followed by adenocarcinoma (10.3\%), gastrointestinal stromal tumour $(2.4 \%)$ and gastric ulcer $(2.0 \%)$. Among chronic gastritis, $47.4 \%$ were H. pylori associated. Moderate to severe activity and inflammation were seen in $45.6 \%$ and $48.4 \%$ respectively. Mucosal atrophy (Atrophic Gastritis) was seen $81.4 \%$ while $19.5 \%$ show complete or incomplete intestinal metaplasia. Conclusion: Helicobacter pylori organism was the common cause of gastric morbidity in our environment, causing chronic gastritis with predominantly mild to moderate grade of inflammation, mucosal atrophy, activity and organisms colonisation.

Key words: Helicobacter pylori, Chronic Gastritis, Adenocarcinoma.

Copyright (C) 2021 The Author(s): This is an open-access article distributed under the terms of the Creative Commons Attribution 4.0 International License (CC BY-NC 4.0) which permits unrestricted use, distribution, and reproduction in any medium for non-commercial use provided the original author and source are credited.

\section{INTRODUCTIONS}

A wide variety of morbid conditions including infectious diseases, inflammatory disorders, vascular pathology, mechanical conditions, toxic and physical reactions including radiation injury and neoplasm do occur in the stomach. To arrive at definitive diagnosis, endoscopic evaluation and biopsy of the lesion is a necessary step while accurate histopathologic examinations of the affected tissue yield satisfactory results [1]. While symptoms and physical signs of such disorder may concur in some cases; the histologic appearance of the different lesions is quite distinct. In addition to arriving at a conclusive diagnosis, gastric biopsies are used in monitoring disease progression, selection of best therapeutic option and prediction of prognosis [2].

Chronic gastritis and its short and long terms sequelae are the predominant lesions seen in gastric biopsies in most reports [3-6]. Helicobacter pylori; a small curved, highly motile gram negative bacillus that survives in the gastric mucosal surfaces within the mucus and gastric pits, has been recognised to be associated with most cases of chronic gastritis [7, 8]. Identification of the aetiolgic factors associated with gastritis and histopathologic characterisation of the various entities associated with further progression of the disease processes used to be arbitrary [2]. Hence the 
Usman Bello \& Abubakar S Maiyaki; Saudi J Pathol Microbiol, Feb, 2021; 6(2): 71-75

introduction of the Sydney system of histopathologic evaluation and classification of chronic gastritis which was later "updated" in Houston [9, 10]. The Sydney system of classification of gastritis encompasses and emphasize on the combined topographical, morphological and aetiological diagnostic information that is reproducible and clinically relevant.

This study document the histopathologic spectrum of diseases in our gastric biopsies specimen, analyse the chronic gastritides using updated Sydney classification and established the role of helicobacter pylori histologically in chronic gastritis.

\section{MATERIALS AND METHOD}

The materials for this study consisted of all the gastric tissue biopsies specimen received in the department of Histopathology Usmanu Danfodiyo University Teaching Hospital Sokoto, over a ten (20112020) year period. These were fixed in $10 \%$ formal saline, processed in paraffin wax and tissue slides stained with hematoxylin and eosin. All cases of chronic gastritis were also stained with Giemsa to enhance easy detection of $\mathrm{H}$. pylori. Cases that shows light microscopic characteristic features of gastric adenocarcinoma identified and characterized as such. The undifferentiated and mesenchymal tumours were subjected to further ancillary investigations mainly immunohistochemical stains including a pancytokeratin; AE1/AE3, $\mathrm{CD}_{117}, \mathrm{CD}_{34}, \mathrm{~S}_{100}$ and $\mathrm{CD}_{3}$, $\mathrm{CD}_{20}$ and $\mathrm{CD}_{23}$. Microscopic features detailing different pathologies were analysed and chronic gastritis were classified based on updated Sydney classification [9]; the following histopathologic features were graded into mild, moderate and severe categories.

- Density of infiltration of the lamina propria with lymphocytes and plasma cells- inflammation

- Density of infiltration of the mucosa with neutrophils - activity

- Degree of glandular atrophy

- Degree and type of intestinal metaplasia

- Density of H pylori colonization

Clinical information on age, sex, duration of disease and endoscopic findings were retrieved from request cards and case folders. Collected data was analyzed using SPSS version 21. Chi-square test (Pearson value) was used for categorical variables. Student's t-test was used to compare means. A P-value of less than 0.05 was considered statistically significant

\section{RESULTS}

Two hundred and fifty two gastric biopsy specimens were received during the study period comprising 137 male and 115 female (M: F = 1.2:1). Their ages ranged from 16 to 82 years and peak in the $6^{\text {th }}$ decade of life with a mean age of 46.5 years (Fig. 1). The predominant diagnosis was chronic gastritis with $85.3 \%$ (215cases). Others include adenocarcinoma
(10.3\%), gastrointestinal stromal tumour $(2.4 \%)$ and gastric ulcer $(2.0 \%)$. There was male preponderance among all the diagnoses except for gastric ulcer (Table $1)$.

There were 215 cases of chronic gastritis. Table II summarises major histopathohlogic characteristic according to updated Sydney classification of the entire cases. Topographically, $86.5 \%$ were antral and fundic only, while $13.5 \%$ of the cases involve incisura angularis. Atrophic changes to the mucosa and mucosal glands was seen in $81.4 \%$ (175 cases), out of which in 102 cases $(47.4 \%)$ of the total CG) H. pylori organisms were identified histologically. In the remaining cases of chronic gastritis (18.6\%) there were neither atrophic changes nor presence of $\mathrm{H}$. pylori organisms. Mild mononuclear infiltrates were observed in $51.6 \%$, moderate inflammations in $31.6 \%$ while severe mucosal infiltrates were recorded in $16.8 \%$. Activity as determined by mucosal neutrophilic infiltrations is; mild $54.4 \%$, moderate $30.7 \%$ and severe $14.9 \%$. Complete intestinal metaplasia was seen in 29 cases $(13.5 \%)$ and incomplete intestinal metaplasia was observed in 13 cases only (6.1\%).

Twenty six cases of gastric adenocarcinoma were documented in this study with 15 cases in male patients and 11 in female. The male to female ratio was 1.4:1. Overall, 21 were conventional intestinal type adenocarcinoma (Table III), four cases were signet ring type carcinoma and a case of diffuse infiltrative carcinoma (linitus plastica). Four cases of gastrointestinal stromal tumour (GIST) were seen in this study. Two of these were spindle cell type and a case each of epithelioid and mixed cells variants. In compliment to the typical histo-morphologic characteristics two cases including one spindle cell type, and the mixed cell types were positive to $\mathrm{CD}_{117}$ and $\mathrm{CD}_{34}$ immunohistochemical markers. However, the other two; one spindle cell and the epithelioid variants were negative to c-kit but positive to $\mathrm{CD}_{34}$, in addition were also negative to $\mathrm{SMA}, \mathrm{AE}_{1} / \mathrm{AE}_{3}$ and $\mathrm{S}_{100}$ hence diagnosed as c-kit negative GIST. Other histopathologic diagnosis includes seven cases of gastric ulcer.

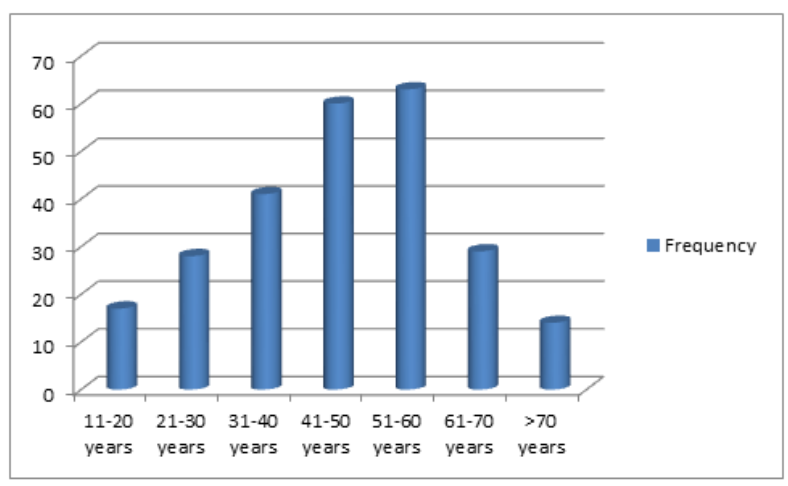

Fig-1: Age distribution 
Table-I: Sex distribution

\begin{tabular}{|l|l|l|l|}
\hline \multirow{2}{*}{ Diagnosis } & \multicolumn{2}{|l|}{ Gender } & \multirow{2}{*}{ Total (\%) } \\
\cline { 2 - 4 } & Male & Female & \\
\hline Chronic Gastritis & 116 & 99 & $215(85.3 \%)$ \\
\hline Adenocarcinoma & 15 & 11 & $26(10.3 \%)$ \\
\hline Gastrointestinal Stromal Tumour (GIST) & 3 & 1 & $4(1.6 \%)$ \\
\hline Gastric Ulcer & 2 & 5 & $7(2.8 \%)$ \\
\hline & $137(54.4 \%)$ & $115(45.6 \%)$ & $252(100 \%)$ \\
\hline
\end{tabular}

Table-II: Histopathohlogic Characteristic According to Updated Sydney Classification

\begin{tabular}{|l|l|l|l|l|}
\hline \multirow{2}{*}{ Histopathologic Feature } & Grade & \multirow{2}{*}{ Total (\%) } \\
\cline { 2 - 5 } & Mild & Moderate & Severe & \\
\hline Inflammation & $111(51.6 \%)$ & $68(31.6 \%)$ & $36(16.8 \%)$ & $215(100)$ \\
\hline Activity & $117(54.4 \%)$ & $66(30.7 \%)$ & $32(14.9 \%)$ & $215(100$ \\
\hline Glandular Atrophy & 108 & 43 & 24 & $175(81.4)$ \\
\hline H. Pylori Colonisation (Density) & 27 & 53 & 17 & $102(47.4)$ \\
\hline Intestinal Metaplasia & \multicolumn{5}{|l}{} \\
\cline { 2 - 4 } Complete & 9 & 16 & 4 & 29 \\
Incomplete & 4 & 7 & 2 & 13 \\
\hline Topography & \multicolumn{5}{|l}{} \\
Antral & 52 & 32 & 24 & $108(52.2 \%)$ \\
Fundic & 54 & 19 & 5 & $78(36.3 \%)$ \\
Incisura angularis & 4 & 7 & 18 & $29(13.5 \%)$ \\
\hline
\end{tabular}

Table-III: Frequency of the Various Histopathologic Diagnoses for Gender

\begin{tabular}{|l|l|l|l|}
\hline \multirow{2}{*}{ Diagnosis } & \multicolumn{2}{l|}{ Gender } & \multirow{2}{*}{ Total (\%) } \\
\cline { 2 - 3 } & Male & Female & \\
\hline Chronic Atrophic H. Pylori gastritis & 60 & 51 & $111(44.1)$ \\
\hline Chronic Atrophic Gastritis with no H. pylori & 36 & 31 & $67(26.6)$ \\
\hline Chronic Non-Atrophic Gastritis & 20 & 17 & $37(14.7)$ \\
\hline Adencarcinoma & & & \\
\hline Intestinal Type & 14 & 9 & $23(9.1)$ \\
\hline Diffuse Type & 1 & 2 & $3(1.2)$ \\
\hline Gastric Ulcer & 2 & 5 & $7(2.8)$ \\
\hline Gastrointestinal Stromal Tumour (GIST) & 3 & 1 & $4(1.6)$ \\
\hline
\end{tabular}

\section{DISCUSSIONS}

The most common histopathologic diagnosis was chronic gastritis with or without specific feature. Chronic gastritis is a special form of inflammation of the gastric mucosal lining characterised by the presence of cells of chronic inflammation in the lamina propria [11]. More than $85 \%(85.3 \%)$ of our cases were due to chronic gastritis; this is comparable to the reports by Udoh et al. in Benin south-south and Duduyemi et al. from Abuja northcentral parts of Nigeria; whom recorded $82.3 \%$ and $76.3 \%$ respectively[12, 13]. Reports from other developing nations such as India, Pakistan, and Kathmandu revealed $82.3 \%, 70 \%$ and $60 \%$ respectively [5, 14, 15]. However, in a sharp contrast to our findings; Anunayi et al. reported a prevalence rate of chronic gastritis at $41.1 \%$ among their endoscopic biopsies [6].

Although there are variety of aetiologies of this form of inflammation, H. pylori is the predominant cause in most cases. H. pylori organisms was seen in
$47.4 \%$ of the index study similar to most reports in Nigeria; however studies in Ibadan revealed an earlier lower rate of $22.4 \%$ by Oluwasola et al. and much later a higher rate of $64 \%$ was recorded by Abiodun et al. in the same centre $[8,16]$. In the later study, both histologic and chemical methods of identification were employed. In contrast to findings, Ayoola et al. report much higher rate of $60.1 \% \mathrm{H}$. pylori infections in patients with chronic gastritis among Saudi populations [7]. However, a more recent study by Zeinab et al. reported prevalence rate of $32.5 \%$ among western Saudi population [17]. In India much higher prevalence of $76.1 \%$ was reported by Hussain et al.[18].

Helicobacter pylori infection affects nearly $50 \%$ of the world population, and has a prevalence range of $15 \%$ to $100 \%$ in some population depending on factors such as age, race, environmental hygiene and socioeconomic status. Helicobacter pylori induced chronic inflammation if allow to continue is usually associated with subsequent mucosal atrophy, regeneration, ulcerations and development of gastric 
Usman Bello \& Abubakar S Maiyaki; Saudi J Pathol Microbiol, Feb, 2021; 6(2): 71-75

cancer, particularly adenocarcinoma [19]. To enhance detection of $\mathrm{H}$. pylori organisms in gastric mucosa, American Gastroenterological Association (AGA) recommends obtaining biopsies in the normal appearing gastric body and antrum of immunocompetent individual with dyspepsia for the detection of $h$ pylori infection [20].

We classify all our cases of chronic gastritis according to Houston Updated Sydney classifications $[2,9,21]$. Antral biopsy dominates topographically while biopsies from incisura angularis were the least in our study. There were few reports regarding topography in gastric biopsies in Nigeria and other African countries. Reports from the few centres in Nigeria that study the topography of gastric biopsies show similar antral predilection [8, 12, 13]. Awwad et al. recorded 75.9\% antral domination among patients attending Arar central hospital in Saudi Arabia, with incisura glandularis having only $15.7 \%$ involvement [22] Beside topography, the Sydney system involves accurate grading of individual parameters; carefully looking at the density of $\mathrm{H}$. pylori colonisation of the mucosa, density of infiltrations of the lamina propria with lymphocytes and plasma cell (inflammation), density of infiltration of the mucosa with neutrophils (activity), degree of intestinal metaplasia and glandular atrophy.

Mild to moderate grades of inflammations and activity dominates severe forms of the disease progression in this study. Similar findings were reported across the country $[12,13]$. However, in Asia and Middle East, contrary to our findings, most reports found severe to moderate inflammation to supersede milder grade of inflammation [17, 18, 21, 23]. This may not be unconnected with careful selection of patients, prior treatment with antibiotic for $\mathrm{H}$. pylori organisms and ethnic and racial differences. For example, Wabinga $\mathrm{H}$. found marked ethnic differences in the severity of H Pylori chronic gastritis and its relationship with the differences in the prevalence of gastric cancer among ethnic groups [24].

Neoplastic conditions of the gastric tissues are not uncommon and in most cases are malignant. We recorded both epithelial and mesenchymal malignant tumours; as it's in all organs line by an epithelial lining; epithelial tumours are far more common. Gastric cancer is one of the leading causes of cancer morbidity and mortality worldwide with wide regional variations depending on factors such as genetic, racial, environmental and prevalence of $\mathrm{H}$. pylori infections [25]. Gastric adenocarcinoma constitutes $10.3 \%$ of our gastric lesions with intestinal type adenocarcinoma forming $88.5 \%$ of the tumour. This is much higher than some reports in Nigeria; Duduyemi et al. reported gastric adenocacinoma in $1.69 \%$ of their gastric biopsies [13]. However, in many parts of the globe, higher prevalence was documented. In Bangledash, $41.35 \%$ of their gastric lesions were primary gastric malignancies; similar higher figures were reported in India, Japan and Saudi Arabia [26-28]. Gastric carcinoma also shows variations within the anatomical parts with marked predilection for antral area [29].

Gastrointestinal stromal tumour (GIST) is the most common mesenchymal tumour of the gastrointestinal tract with frequencies between $60-80 \%$ [30]. In Lagos, Nigeria GIST was reported as the most common mesenchymal tumour of the GIT constituting $41 \%$ [31]. This tumour is however only about $1 \%$ of all malignancies of gastrointestinal tract [29]. The tumour shows some morphological challenges because of its histogenesis and in most cases, the final diagnosis is based on its unique immunohistochemical profile. In Enugu, for example out of the 7 cases with morphological features of GIST only 2 cases fulfil all the criteria for GIST as reported by Ezeome et al. [31] All our cases fulfil the diagnostic criteria for GIST; while two were c-kit positive GIST, the other two cases were c-kit negative GIST.

Histopathologic evaluation of gastric biopsies using a standardised method that is reproducible and clinically relevant in treatment and monitoring disease progression is an all important tool in the proper management of patient with upper gastrointestinal tract diseases. Helicobacter pylori plays an important role in our setting in this regard and should be identified early in order to curtail the short and long term consequences of disease progression to more debilitating pathologic conditions especially adenocarcinoma.

\section{REFERENCES}

1. Ahn, S., \& Park, D. Y. (2016). Practical points in gastric pathology. Archives of Pathology \& Laboratory Medicine, 140(5), 397-405.

2. Stolte, M., \& Meining, A. (2001). The updated Sydney system: classification and grading of gastritis as the basis of diagnosis and treatment. Canadian journal of gastroenterology, 15.

3. Sheikh, B. A., Hamdani, S. M., \& Malik, R. (2015). Histopathological spectrum of lesions of upper gastrointestinal tract: a study of endoscopic biopsies. Global J Med Public Health, 4(4), 1-8.

4. Krishnappa, R., Horakerappa, M. S., Ali, K., \& Gouri, M. (2013). A study on histopathological spectrum of upper gastrointestinal tract endoscopic biopsies. International Journal of Medical Research \& Health Sciences, 2(3), 418-424.

5. Singh, P., Goswami, K. C., \& Gupta, B. B. (2016). Gastric mucosal biopsies in non-ulcer dyspepsia: A histopathologic study. Asian Journal of Medical Sciences, 7(2), 80-84.

6. Jeshadi, A., Mohammad, A. M., Kadaru, M. R., Nagamuthu, E. R., Kalangi, H., \& Boddu, A. (2016). Study of gastric biopsies with clinicopathological correlation-A tertiary care centre experience. J Evid Based Med Healthc, 3, 2937-2940.

7. Ayoola, A. E., Ageely, H. M., Gadour, M. O., \& Pathak, V. P. (2004). Prevalence of Helicobacter 
Usman Bello \& Abubakar S Maiyaki; Saudi J Pathol Microbiol, Feb, 2021; 6(2): 71-75

pylori infection among patients with dyspepsia in South-Western Saudi Arabia. Saudi medical journal, 25(10), 1433.

8. Jemilohun, A. C., Otegbayo, J. A., Ola, S. O., Oluwasola, O. A., \& Akere, A. (2010). Prevalence of Helicobacter pylori among Nigerian patients with dyspepsia in Ibadan. Pan African Medical Journal, 6(1).

9. Dixon, M. F., Genta, R. M., Yardley, J. H., \& Correa, P. (1996). Classification and grading of gastritis: the updated Sydney system. The American journal of surgical pathology, 20(10), 1161-1181.

10. Suzana, M. K., Skender, T., Emine, D. S., Halil, A., Vjollca, S. M., Agron, K., \& Arijeta, P. (2009). Helicobacter pylori gastritis updated Sydney classification applied in our material. Sec Biol Med Sci, 30(1), 45-60.

11. Kayaçetin, S., \& Güreşçi, S. (2014). What is gastritis? What is gastropathy? How is it classified? Turk $\mathbf{J}$ Gastroenterol, 25(3), 233-47.

12. Udoh, M. O., \& Obaseki, D. E. (2012). Histopathological evaluation of $\mathrm{H}$. pylori associated gastric lesions in Benin city, Nigeria. East African medical journal, 89(12), 408-413.

13. Duduyemi, B. M., Ojo, B. A., Olaomi, O. O., \& Atiba, A. S. (2014). Histopathological pattern of endoscopic gastric biopsy in a district hospital in Nigeria: a review of 118 consecutive cases. Am J Med Biol Res, 2(3), 83-86.

14. Sarfraz, T., Hafeez, M., Shafiq, N., Tariq, H., Azhar, M., Ahmed, K. N., \& Jamal, N. (2016). Histopathological analysis of gastric mucosal biopsies in non-ulcer dyspepsia. Pakistan Armed Forces Medical Journal, 66(6), 857-61.

15. Sharma, S., Makaju, R., Dhakal, R., Purbey, B., Gurung, R. B., \& Shrestha, R. (2015). Correlation between endoscopic and histopathological findings in gastric lesions. Kathmandu University Medical Journal, 13(3), 216-219.

16. Oluwasola, A. O., \& Ogunbiyi, J. O. (2004). Chronic gastritis and Helicobacter pylori infection in University College Hospital Ibadan, Nigeria--a study of 85 fibre optic gastric biopsies. Nigerian journal of medicine: journal of the National Association of Resident Doctors of Nigeria, 13(4), 372-378.

17. Elsawaf, Z. M., Albasri, A. M., Hussainy, A. S., \& Alhujaily, A. S. (2017). Histopathological pattern of benign endoscopic gastric biopsies in Western Saudi Arabia: A review of 1236 cases. JPMA, 67(252).

18. Hussain, S. I., Reshi, R., Akhter, G., \& Beigh, A. (2015). Clinico histopathological study of upper gastrointestinal tract endoscopic biopsies. International Journal of Current Research and Review, 7(16), 78.

19. Saber, T., Ghonaim, M. M., Yousef, A. R., Khalifa, A., Al Qurashi, H., Shaqhan, M., \& Samaha, M. (2015). Association of helicobacter pylori caga gene with gastric cancer and peptic ulcer in saudi patients. J. Microbiol. Biotechnol, 25(7), 1146-1153.
20. Yu-Xiao, Y., Joel, B., Prashant, K., Grigorios, L., \& the Clinical Guidelines Committee. (2015). American Gastroenterological Association Institute Guideline on the Role of Upper Gastrointestinal Biopsy to Evaluate Dyspepsia in the Adult Patient in the Absence of Visible Mucosal Lesions. Gastroenterol, 149:1082-1087

21. Zacharie, S., Magloire, B.S., Paul, A.A., Fid`ele, V., Christophe, M., Hortense, K.G., Grace, N., \& JeanLouis, E.O. (2014). Intra- and Interobserver Reproducibility of Grading of Helicobacter pylori Gastritis According to the Updated Sydney System. African J Pathol Microbiol, 3:1-5

22. ALenezy, A. K., \& Hassan, T. M. (2014). Heliclobacter pylori associated chronic gastritis: Endoscopic and pathological findings, comparative study. International Journal of Genetics and Molecular Biology, 6(2), 23-28.

23. Yakoob, M. Y., \& Hussainy, A. S. (2010). Chronic gastritis and Helicobacter pylori: a histopathological study of gastric mucosal biopsies. JCPSP: Journal of the College of Physicians and Surgeons Pakistan, 20(11), 773.

24. Wabinga, H. (2005). Helicobacter pylori and histopathological changes of gastric mucosa in Uganda population with varying prevalence of stomach cancer. African health sciences, 5(3), 234237.

25. Fujita, H., Lennerz, J. K., Chung, D. C., Patel, D., Deshpande, V., Yoon, S. S., \& Lauwers, G. Y. (2012). Endoscopic surveillance of patients with hereditary diffuse gastric cancer: biopsy recommendations after topographic distribution of cancer foci in a series of 10 CDH1-mutated gastrectomies. The American journal of surgical pathology, 36(11), 1709-1717.

26. Islam, S. M. J., Ali, S. M., Ahmed, S., Afroz, Q. D., Chowdhury, R., \& Huda, M. (2009). Histopathologic pattern of gastric cancer in Bangladesh. Journal of Armed Forces Medical College, Bangladesh, 5(1), 2124.

27. Manasa, G. C., \& Sunila, M. G. (2016). Histopathological study of gastric carcinoma with associated precursor lesions. Indian Journal of Pathology and Oncology, 3(1), 26-31.

28. Hamdi, J., \& Morad, N. A. (1994). Gastric cancer in southern Saudi Arabia. Annals of Saudi medicine, 14(3), 195-197.

29. Quaas, A. (2017). Malignant Gastric Tumours: The Role of Pathologist in the Diagnosis and for Therapeutic Decisions. Gastric Cancer, 267.

30. Abdulkareem, F. B., Rotimi, O., Elesha, S. O., \& Banjo, A. A. F. (2009). Immunophenotyping of gastrointestinal mesenchymal tumours in Lagos, Nigeria. West African journal of medicine, 28(6).

31. Ezeome, E. R., Olusina, D. B., \& Igbokwe, U. O. (2010). Gastrointestinal stromal tumours at the University of Nigeriateaching Hospital Enugu, Nigeria: an immunohistochemical study of gitmesenchymal tumours. Nigerian journal of clinical practice, 13(3). 